\title{
CONF-950412--20
}

UCRL-JC-118841

L-19399-1

PREPRINT

\section{Rapid Growth of Diamond-Like-Carbon Films by Copper Vapor Laser Ablation}

\author{
W. McLean \\ B. E. Warner \\ M. A. Havstad \\ M. Balooch \\ Lawrence Livermore National Laboratory \\ Livermore, CA
}

This paper was prepared for submittal to the

Materials Research Society

San Francisco, CA

April 17- 21, 1995

April 1995

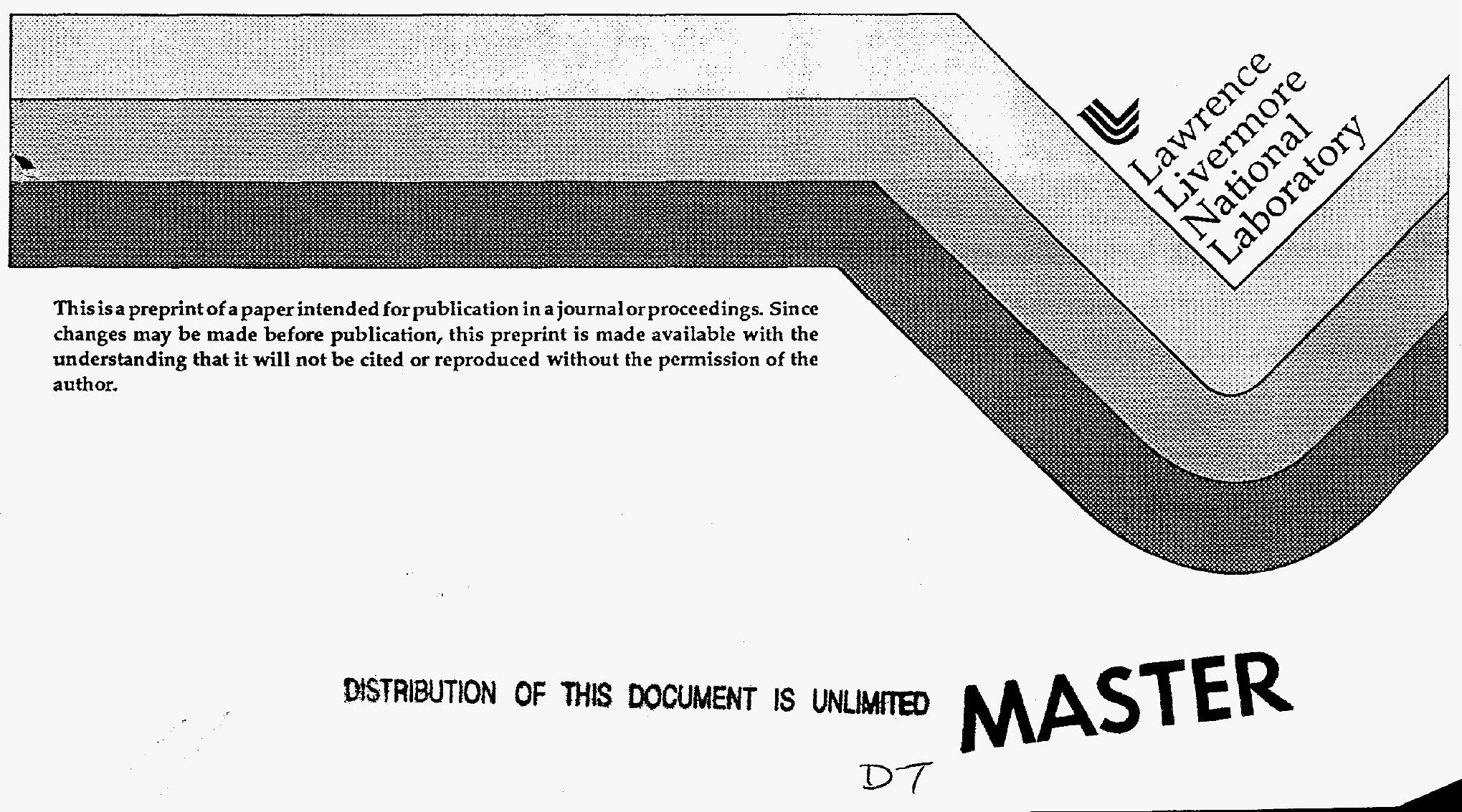




\section{DISCLAIMER}

This document was prepared as an account of work sponsored by an agency of the United States Government. Neither the United States Government nor the University of California nor any of their employees, makes any warranty, express or implied, or assumes any legal liability or responsibility for the accuracy, completeness, or usefulness of any information, apparatus, product, or process disclosed, or represents that its use would not infringe privately owned rights. Reference herein to any specific commercial products, process, or service by trade name, trademark, manufacturer, or otherwise, does not necessarily constitute or imply its endorsement, recommendation, or favoring by the United States Government or the University of California. The views and opinions of authors expressed herein do not necessarily state or reflect those of the United States Govemment or the University of Califomia, and shall not be used for advertising or product endorsement purposes. 


\section{DISCLAIMER}

Portions of this document may be illegible in electronic image products. Images are produced from the best available original document. 


\title{
RAPID GROWTH OF DIAMOND-LIKE-CARBON FILMS \\ BY COPPER VAPOR LASER ABLATION
}

W. MCLEAN, B. E. WARNER, M. A. HAVSTAD, M. BALOOCH

University of California, Lawrence Livermore National Laboratory, P.O. Box 808, L-460, Livermore, CA, 94550.

\begin{abstract}
Visible light from a copper vapor laser (CVL) operating with 510 and $578 \mathrm{~nm}$ radiation (intensity ratio approximately $2: 1$ ), an average power of $100 \mathrm{~W}$, a pulse duration of $50 \mathrm{~ns}$; and a repetition frequency of $4.4 \mathrm{kHz}$ has been shown to produce high quality diamond-like-carbon (DLC) films at fluences between $2 \times 10^{8}$ and $5 \times 10^{10} \mathrm{~W} / \mathrm{cm}^{2}$. Maximum deposition rates of 2000 $\mu \mathrm{m} \cdot \mathrm{cm}^{2} / \mathrm{h}$ were obtained at $5 \times 10^{8} \mathrm{~W} / \mathrm{cm}^{2}$. DLC films with hardness values of approximately 60 $\mathrm{GPa}$ were characterized by a variety of techniques to confirm DLC character, hydrogen content, and surface morphology. The presence of $\mathrm{C}_{2}$ in the vapor plume was confirmed by the presence of the $\mathrm{C}_{2}$ Swan bands in emission spectra obtained during the process. Economic implications of process scale-up to industrially meaningful component sizes are presented.
\end{abstract}

\section{INTRODUCTION}

PLD of DLC films has been demonstrated with both ultraviolet and infrared light from both excimer and Nd:YAG lasers ${ }^{1-5}$ with irradiances on the ablation target of $2 \times 10^{8}$ to over $10^{11}$ $\mathrm{W} / \mathrm{cm}^{2}$ respectively. One major impediment to commercialization of PLD processes for DLC (and other materials as well) is the rate at which material can be deposited on a substrate by these commercially available photon sources. This issue has been addressed by employing the visible light output of high power CVLs. By demonstrating peak deposition rates on the order of 1 $\mu \mathrm{m} / \mathrm{min}$, this work lays the foundation for follow-on development of PLD processes by less complex pulsed lasers operating in the visible wavelength regions at high pulse repetition frequencies (PRFs).

\section{EXPERIMENTAL PROCEDURES}

The characteristics of the CVLs employed in this work are summarized in Table I. Approximately $190 \mathrm{~W}$ (average power) of light from a single CVL oscillator and $500 \mathrm{~W}$ amplifier was directed through a fused $\mathrm{SiO}_{2}$ window to a vacuum chamber on a rotating graphite target (POCO AXM-5Q, $5 \mu \mathrm{m}$ average particle size) moving at a speed of $8 \mathrm{~cm} / \mathrm{s}$. Target texturing was minimized by exposing fresh tracks of graphite by indexing the target one beam diameter every revolution. Substrates were biased to $-500 \mathrm{~V}$ during the ablation process and to $+40 \mathrm{~V}$ between laser pulses.

Table I. CVL Operating Parameters

$\begin{array}{ll}\text { Wavelength } & 510,578 \mathrm{~nm}(2: 1 \text { intensity ratio) } \\ \text { Pulse Width } & 50 \mathrm{~ns} \text { (FWHM) } \\ \text { Pulse Energy } & 25 \mathrm{~mJ} \\ \text { Pulse Repetition Frequency } & 4400 \mathrm{~Hz}\end{array}$


A $500 \mathrm{~mm}$ focusing lens outside the vacuum chamber was used to set peak irradiances on the target by adjusting the beam diameter from $50 \mu \mathrm{m}\left(5 \times 10^{10} \mathrm{~W} / \mathrm{cm}^{2}\right)$ to $750 \mu \mathrm{m}\left(2 \times 10^{8} \mathrm{~W} / \mathrm{cm}^{2}\right)$. Target-to-substrate spacing was typically $7.6 \mathrm{~cm}$. Film thickness and distribution data on $\mathrm{Si}(100)$. substrates were obtained by masking the substrates and measuring the step height from the bare $\mathrm{Si}$ to the coating surface with a standard laboratory profilometer. All depositions were performed at ambient temperature in a vacuum of $5 \times 10^{-7}$ torr or better.

\section{RESULTS AND DISCUSSION}

Electron Energy Loss Spectra (EELS) were recorded for primary beam energies of $495 \mathrm{eV}$ and analyzed with a single pass cylindrical mirror analyzer. A typical spectrum of DLC, in this case a $250 \mathrm{~nm}$ thick film grown at $6 \times 10^{8} \mathrm{~W} / \mathrm{cm} 2$ [Fig. 1(a)], show the absence of the $\pi \rightarrow \pi * \operatorname{loss}$ feature $6 \mathrm{eV}$ below the reflected primary beam. The absence of this feaure is characteristic of $\mathrm{sp}^{3}$ bonded material [Fig. 1(b)] ${ }^{6,7}$ DLC coatings grown at fluences ranging from $2 \times 10^{8}$ to $5 \times 10^{10}$ $\mathrm{W} / \mathrm{cm}^{2}$ exhibited similar characteristics. Raman spectra from these specimens exhibited the asymmetric peak at $1550 \mathrm{~cm}^{-1}$ characteristic of DLC [Fig. 1(c)]. ${ }^{8}$
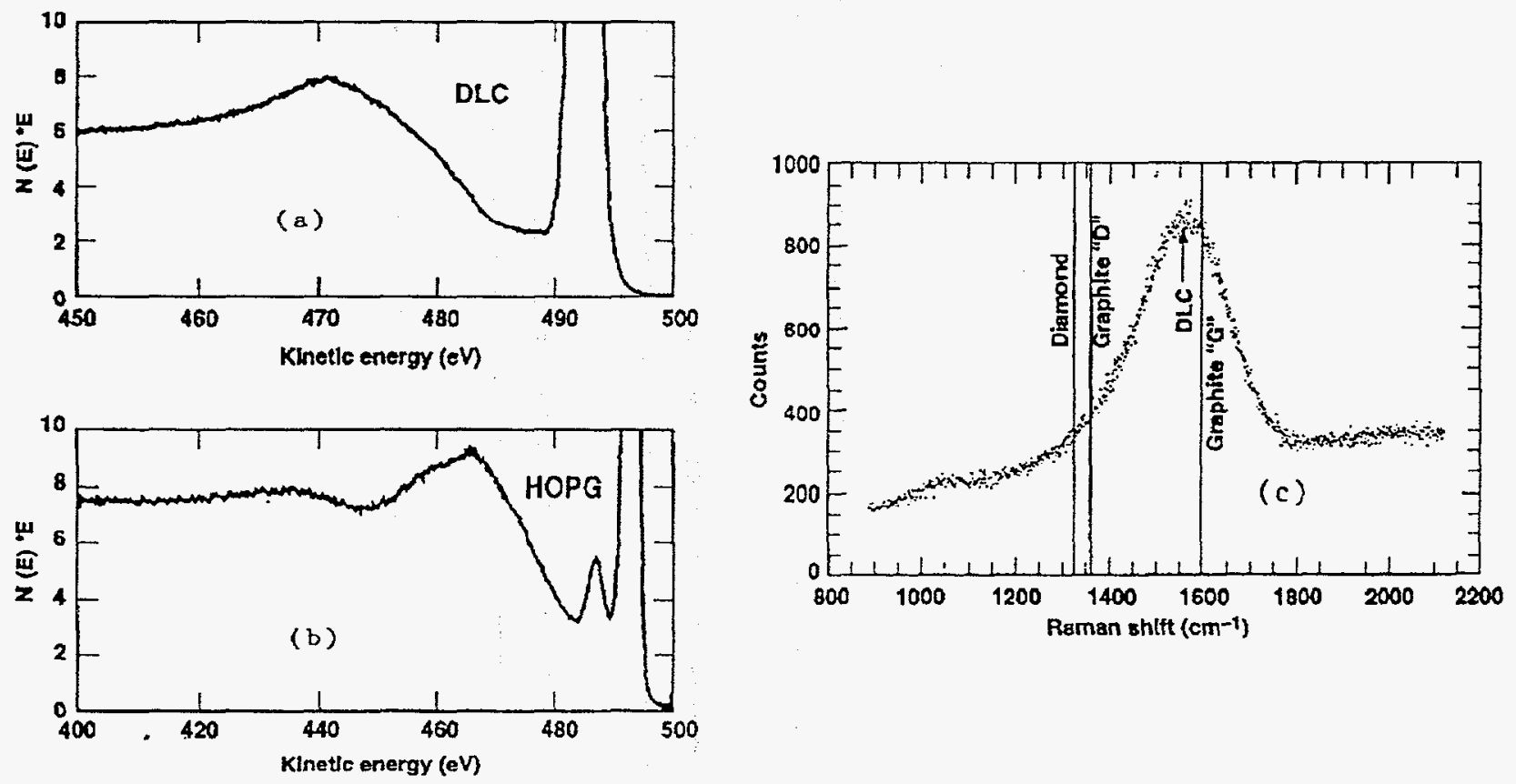

Figure 1. Characterization of DLC and graphite. (a) EELS of DLC grown at $5 \times 10^{8} \mathrm{~W} / \mathrm{cm}^{2}$. (b) EELS of highly oriented pyrolytic graphite. (c) Raman spectrum of DLC from (a).

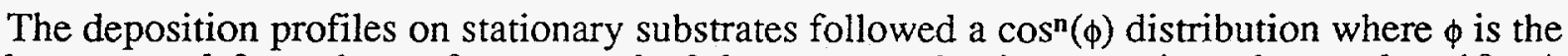
angle measured from the surface normal of the target and $\mathbf{n}$ is approximately equal to 10 . A typical deposition profile resulting from 100,000 pulses (i. e., $23 \mathrm{~s}$ of laser-on time) at $5 \times 10^{8}$ $\mathrm{W} / \mathrm{cm}^{2}$ is illustrated in Fig. 2(a). Integration of the volume defined by this curve yields a volume deposition rate of approximately $2000 \mu \mathrm{m} \cdot \mathrm{cm}^{2} / \mathrm{h}$. The variation of peak deposition rate with fluence is illustrated in Fig. 2(b). The rate increases with fluence up to $5 \times 10^{8} \mathrm{~W} / \mathrm{cm}^{2}$. Beyond this level, it is believed that photon interaction with the ablation plume begins to mask the target and the effective coating rate decreases. No differences in the EELS or Raman spectra of material grown under the range of fluences investigated could be detected. 

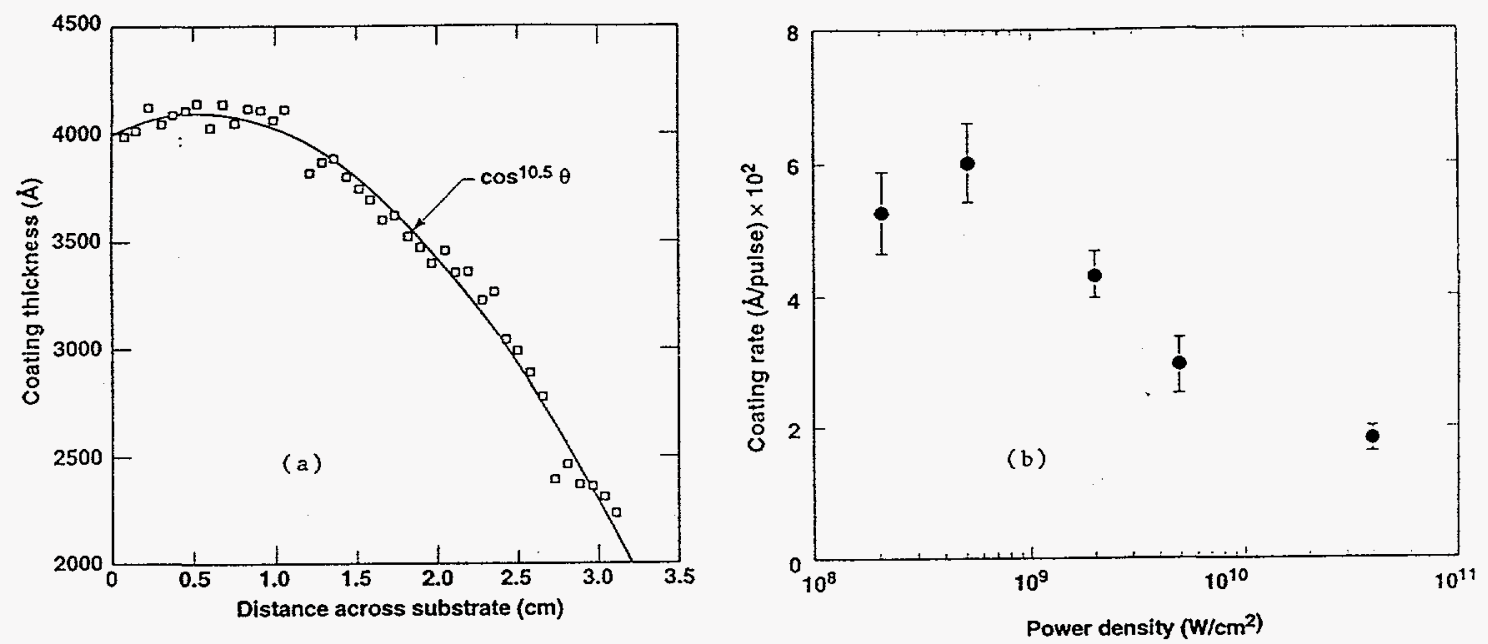

Figure 2. (a) Spatial distribution of DLC grown on a Si(100) substrate after 100,000 laser shots at $190 \mathrm{~W}$ average power and $5 \times 10^{8} \mathrm{~W} / \mathrm{cm}^{2}$.

(b) Variation of peak coating rate with fluence.

In agreement with other investigations at similar laser fluence (but shorter wavelength [ 248 $\mathrm{nm}]$ and higher pulse energy $[250 \mathrm{~mJ}]),{ }^{9}$ the emission spectra obtained from the laser plume viewed parallel to the target surface were found to be dominated by the $\mathrm{C}_{2}$ vibrational bands. ${ }^{10}$ The $\Delta v=+1$ spectrum of the $\mathrm{C}_{2}$ Swan bands at $473 \mathrm{~nm}$ is shown in Fig. 3. The intensity of the 1,0 line the was seen to roughly correlate with the coating rate measured at the substrate surface. Low and high resolution atomic force microscope images of typical DLC films are shown in Fig. 4. The characteristic grain size is on the order of $150 \mathrm{~nm}$, and the rms surface roughness is less than $10 \mathrm{~nm}$. Although large areas showing no macroscopic inclusions were found, typical $40 \mu \mathrm{m}$ by $40 \mu \mathrm{m}$ areas contained $2-8$ macro particles with an average height of $200 \pm 50 \mathrm{~nm}$ and width of $50 \pm 10 \mathrm{~nm}$.

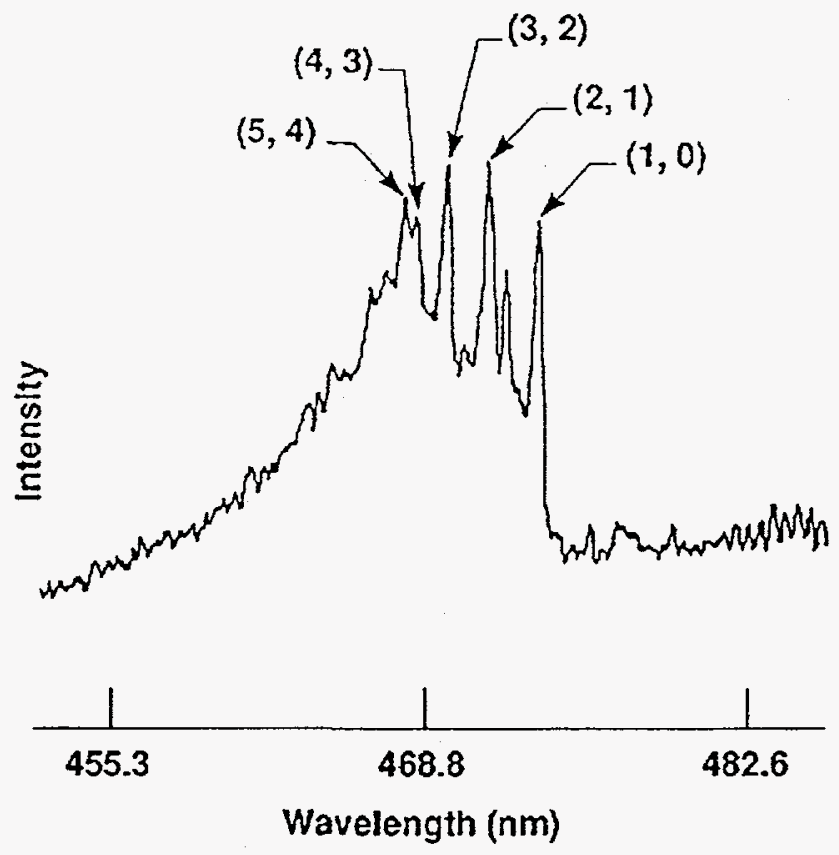

Figure 3. Optical Emission from the $\mathrm{C}_{2}$ Swan bands during ablation at $5 \times 10^{8} \mathrm{~W} / \mathrm{cm}^{2}$. 

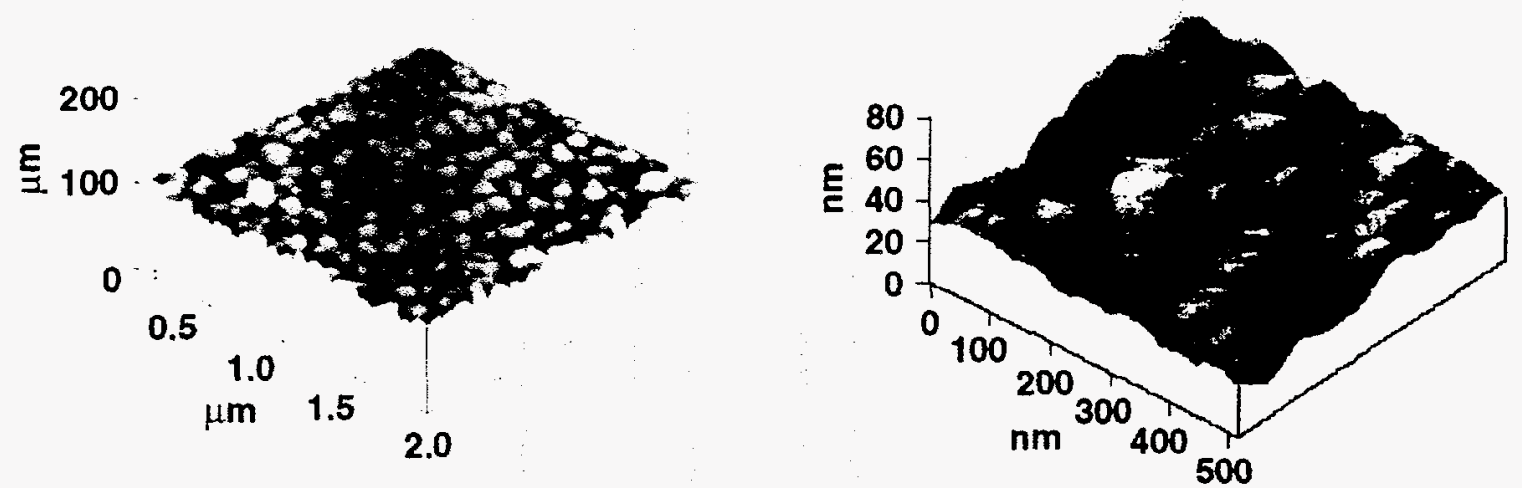

Figure 4. Surface morphology of DLC by AFM at low and high magnification.

A noteworthy companion to most violent PLD processes is the unwanted generation of large particles and their incorporation in the condensed films. It is believed that deep target penetration at the high powers typical of most PLD processes results in macroparticle generation by explosive removal of material around the periphery of the laser spot. ${ }^{11}$ By employing relatively low energies per pulse (on the order of $25 \mathrm{~mJ}$ ), roughly $0.1 \mu \mathrm{m} /$ pulse (1015 atoms) depth was removed from the graphite target surface at maximum deposition rates. Approximately $1.5 \times 10^{-6}$ coulombs were collected on the biased target per laser pulse, corresponding to a fraction ionized of $1 \%$. If the target speed is adjusted so that no more than 2 $\mu \mathrm{m}$ of graphite is removed from the target prior to exposing fresh material, the generation of large particles appears to be suppressed. This observation is based on the presence of large incandescent particles in the field of view parallel to the target surface at dwell times that allow drilling to greater depths, and, conversely, their absence at shorter dwell times. Inspections of target surfaces by AFM and optical microscopy provide additional support for this hypothesis.

Examination of DLC by forward recoil spectroscopy (FRS) of hydrogen by a $2.9 \mathrm{MeV} \mathrm{He}{ }^{+}$ beam revealed that the bulk of the material contained little, if any, hydrogen. Monolayer quantities of hydrogen (Fig. 5) were detected at the Si:DLC and DLC:vacuum interfaces. It has been suggested that the hardness of DLC films is inversely proportional to their hydrogen content. ${ }^{12}$ Hardness of DLC from this study was characterized by a nanoindentation technique utilizing a diamond tipped AFM probe and found to be approximately $60 \mathrm{GPa}$. An AFM line trace through an indentation made with an applied force of $1.2 \times 10^{-3} \mathrm{~N}$ is shown in Fig. 6.

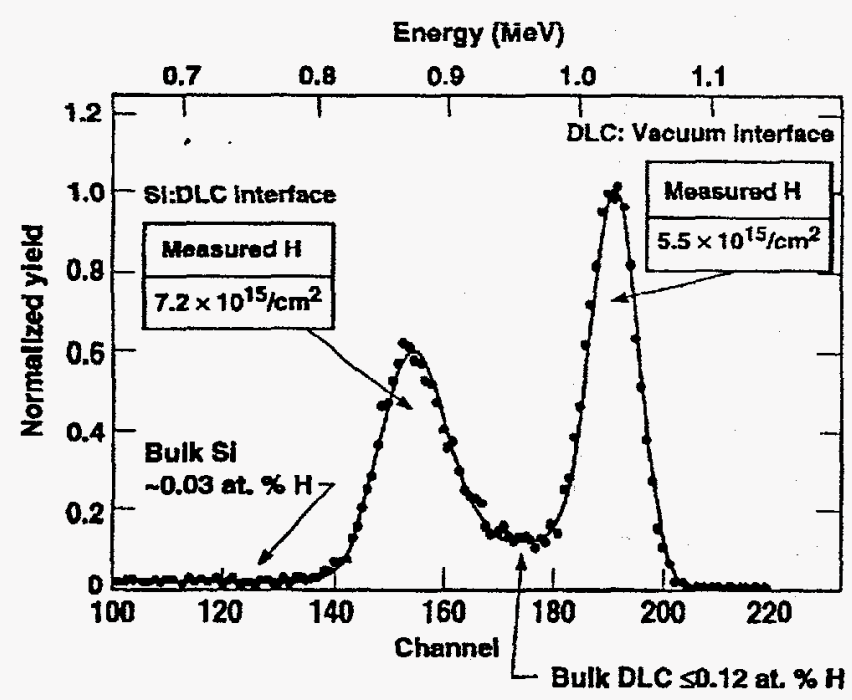

Figure 5. Forward recoil spectroscopy reveals presence of monolayers of $\mathrm{H}$ at DLC interfaces.

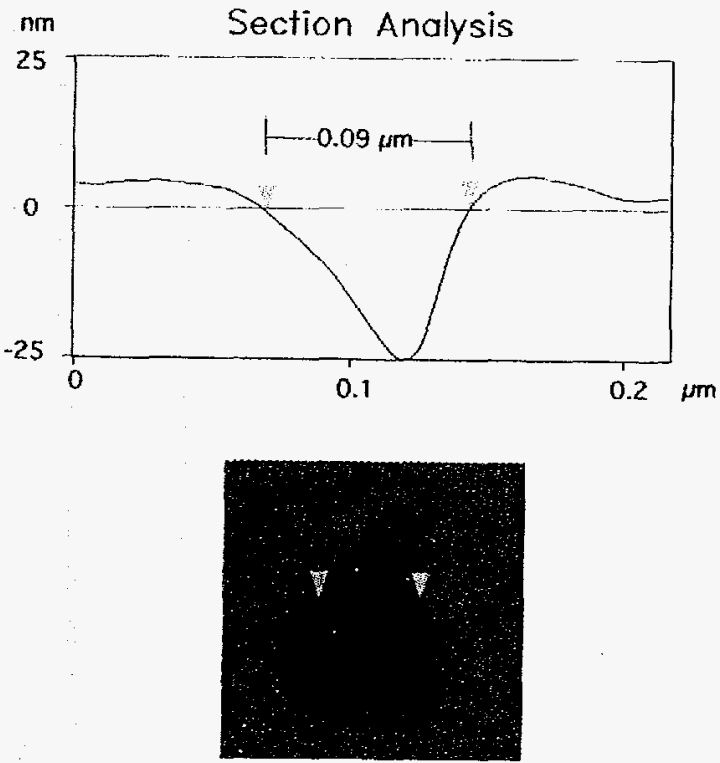

Figure 6. Nanoindentations in DLC show hardness to be $60 \mathrm{Gpa}$. 
Deposition of DLC with visible light from high repetition rate copper vapor lasers has been demonstrated to be an efficient and effective method for coating specimens. DLC produced by this process at fluences of approximately $5 \times 10^{8} \mathrm{~W} / \mathrm{cm}^{2}$ are smooth $(10 \mathrm{~nm} \mathrm{rms}$ roughness), hard (60 GPa) and economical to apply. Coating rates of $2000 \mu \mathrm{m} \cdot \mathrm{cm}^{2} / \mathrm{h}$ at $190 \mathrm{~W}$ average laser power set the stage for scaling this technology up to a practical industrial coating tool with the 500 W CVL sources developed at LLNL.

\section{ACKNOWLEDGMENTS}

The authors wish to thank L. J. Bernardez of Sandia National Laboratory, Livermore for the Raman spectra and M. A. Schildbach, and R. G. Musket of LLNL for the EELS and forward recoil spectra, respectively. In addition, they wish to thank E. P. Dragon and E. J. Fehring of LLNL for the excellent technical support.

This work was performed under the auspices of the U.S. Department of Energy by the Lawrence Livermore National Laboratory under Contract W-7405-ENG-48.

\section{REFERENCES}

1 T. Sato, S. Furuno, S. Iguchi, and M. Hanabusa, Appl. Phys. A 45, 335 (1988).

2. J. Krishnaswamy, A. Rengan, J. Narayan, K. Vedam, and C. J. McHargue, Appl. Phys. Lett 54,2455 (1989).

3. P. T. Murray and D. T. Peeler, Appl. Surface Sci. 69, 225 (1993).

4. P. T. Murray and D. T. Peeler, J. Elec. Mater., 23, 855 (1994).

5. C. B. Collins, F. Davanloo, E. M. Juengerman, W. R. Osborn, and D. R. Jander, Appl. Phys. Lett. 54, 216 (1989).

6. J. Robertson, Adv. in Phys. 4, 317 (1986).

7. N. Savvides, Mater. Sci. Forum, 52\&53, 407 (1989).

8. H. -C. Tsai and D. B. Bogey, J. Vac. Sci. Technol. A 5, 3787 (1987).

9. X. Chen, J. Mazumder, and A. Purohit, Appl. Phys. 52, 328 (1991).

10. L. V. Berzins, Lawrence Livermore National Laboratory (private communication).

11. C. D. Boley and J. T. Early, Lawrence Livermore National Laboratory, UCRL-JC-117078 (1994).

12. F. Jansen, M. Machonkin, S. Kaplan, and S. Hark, J. Vac. Sci. Technol. A 3, 605 (1985). 